\title{
Scientific Programme
}

\section{NETTAB 2012 \\ Workshop on "Integrated Bio-Search"}

14-16 November 2012, Como, Italy

http://www.nettah.org/2012/ 


\title{
Scientific Programme
}

\author{
Wednesday November 14 \\ $9.00-10.50$ Tutorial 1 \\ Multi-scale data integration and virtual exploration from promoters, through \\ networks to drug targets \\ Alexander Kel, GeneXplain GmbH, Wolfenbüttel, Germany, and Biosoft.ru, \\ Skolkovo Center of Bioinformatics, Novosibirsk, Russian Federation
$10.50-11.10$ Break
$11.10-13.00$ Tutorial 2
The Taverna Workbench: Integrating and analysing biological and clinical data with computerised workflows
Katy Wolstencroft University of Manchester, United Kingdom \\ 13.30 - 14.20 Registration and poster hang-up \\ $14.20-14.30$ Welcome and Introduction \\ $14.30-15.10$ Invited Lecture \\ Integration and analysis of multi-type high-throughput data for biomolecular \\ knowledge discovery \\ Erik Bongcam-Rudloff, Swedish University of Agricultural Sciences, and Uppsala \\ University, Sweden \\ $15.10-15.50$ Scientific Session 1 \\ Using graph theory to analyze gene network coherence \\ Francisco Gómez-Vela Norberto Díaz-Díaz, Jose Antonio Lagares, Jose Antonio \\ Sánchez and Jesús S. Aguilar-Ruiz \\ Network-based gene-disease prioritization using PROPHNET \\ Víctor Martínez, Carlos Cano and Armando Blanco \\ 15.50 - 16.20 Coffee Break \\ 16.20 - 18.15 Scientific Session 2 \\ Rational design of organelle compartments in cells \\ Claudio Angione, Giovanni Carapezza, Jole Costanza, Pietro Lio' and Giuseppe \\ Nicosia \\ Filtering with alignment free distances for high throughput DNA reads \\ assembly \\ Maria Cristina De Cola, Giovanni Felici, Daniele Santoni and Emanuel Weitschek \\ A strategy to reduce technical variability and bias in RNA sequencing data \\ Francesca Finotello, Enrico Lavezzo, Luisa Barzon, Paolo Mazzon, Paolo \\ Fontana, Stefano Toppo, Barbara Di Camillo \\ Applications of a generic model of genomic variations functional analysis \\ Sarah N. Mapelli, Uberto Pozzoli \\ The Biovel project: robust phylogenetic workflows running on the Grid \\ Saverio Vicario, Bachir Balech Giacinto Donvito, Pasquale Notarangelo, \\ Graziano Pesole \\ Ranking-aware integration and explorative search of distributed bio-data \\ Marco Masseroli, Matteo Picozzi and Giorgio Ghisalberti \\ Development of a text search engine for medicinal chemistry patents \\ Emilie Pasche, Julien Gobeill, Fatma Oezdemir-Zaech, Therese Vachon, \\ Christian Lovis and Patrick Ruch
}




\section{Thursday November 15}

$8.30-9.00$ Registration and poster hang-up

$9.00-9.40 \quad$ Invited Lecture

Semantics based biomedical knowledge search, integration and discovery Barend Mons, Leiden University Medical Center, and Netherlands Bioinformatics Center, The Netherlands

$9.40-10.20$ Scientific Session 3

Answering Gene Ontology terms to proteomics questions by supervised macro reading in Medline

Julien Gobeill, Emilie Pasche, Douglas Teodoro, Anne-Lise Veuthey and Patrick Ruch

IntelliGenWiki: An Intelligent Semantic Wiki for Life Sciences

Bahar Sateli, Marie-Jean Meurs, Gregory Butler, Justin Powlowski, Adrian Tsang and René Witte

10.20 - 12.00 Poster and Software Demonstration Session with Coffee Break

12.00 - 13.00 Technological - Industrial Session

Extracting knowledge from biomedical data through Logic Learning Machines and Rulex

Marco Muselli

Data modeling: the key to biological data integration

François Rechenmann

GeneGrid: finding disease causing variants in NGS data

Jochen Supper, Claudia Gugenmus, Korbinian Grote and Frederic Eyber

$13.00-14.00 \quad$ Lunch Break

$14.00-15.30$ Panel Discussion

Technological and methodological challenges for Integrated Bio-Search

Erik Bongcam-Rudloff, Barend Mons, Eric Neumann, Alexander Kel, François

Rechenmann, and Stefano Ceri introduce the topic, then open discussion

follows

$15.30-19.00$ Guided tour of Como and of the Educational Silk Museum of Como

20.00 - 23.00 Social Dinner 


\begin{tabular}{|c|c|}
\hline Friday & November 16 \\
\hline \multirow[t]{2}{*}{$9.00-9.40$} & Invited Lecture \\
\hline & $\begin{array}{l}\text { Clinical and genomic data integration in support of biomedical research } \\
\text { and clinical practice } \\
\text { Eric Neumann PanGenX and Clinical Semantics Technologies, USA }\end{array}$ \\
\hline \multirow[t]{4}{*}{$9.40-10.40$} & Scientific Session 4 \\
\hline & $\begin{array}{l}\text { ROCK: a resource for integrative breast cancer data analysis } \\
\text { Marketa Zvelebil, Costas Mitsopoulos and Saif Ur-Rehman }\end{array}$ \\
\hline & $\begin{array}{l}\text { QTreds: a flexible LIMS for omics laboratories } \\
\text { Piergiorgio Palla, Gianfranco Frau, Laura Vargiu and Patricia Rodriguez-Tomé }\end{array}$ \\
\hline & $\begin{array}{l}\text { The open source ISA software suite and its international user community: } \\
\text { knowledge management of experimental data } \\
\text { Alejandra Gonzalez-Beltran, Eamonn Maguire, Philippe Rocca-Serra and } \\
\text { Susanna-Assunta Sansone }\end{array}$ \\
\hline $10.40-11.10$ & Coffee Break \\
\hline \multirow[t]{5}{*}{$11.10-12.30$} & Scientific Session 5 \\
\hline & $\begin{array}{l}\text { The ontogene system: an advanced information extraction application for } \\
\text { biological literature } \\
\text { Fabio Rinaldi }\end{array}$ \\
\hline & $\begin{array}{l}\text { A semantic collaborative system for the management of translational } \\
\text { research projects } \\
\text { Matteo Gabetta, Giuseppe Milani, Cristiana Larizza, Valentina Favalli, Eloisa } \\
\text { Arbustini and Riccardo Bellazzi }\end{array}$ \\
\hline & $\begin{array}{l}\text { BioQuery-ASP: querying biomedical databases and ontologies using } \\
\text { Answer Set Programming } \\
\text { Esra Erdem, Umut Oztok }\end{array}$ \\
\hline & $\begin{array}{l}\text { DiGSNP: a web tool for Disease-Gene-SNP hierarchical prioritization } \\
\text { Carmen Navarro, Carlos Cano, Armando Blanco, Fernando García }\end{array}$ \\
\hline $12.30-13.00$ & Announcement of NETTAB 2013 and Farewell \\
\hline
\end{tabular}

